\title{
Variable Structure Controller for Generator Side Converter of Variable Speed PMSG Wind Energy Conversion System
}

\author{
K. Rama Lingeswara Prasad \\ Assoc.Professor \\ Dept.of Electrical \& Electronics Engineering, \\ Lakireddy Bali Reddy College of Engineering, \\ Mylavaram, AP, India.
}

\author{
K. Chandra Sekhar, PhD. \\ Professsor\&HOD \\ Dept.of Electrical \& Electronics Engineering, \\ RVR \& JC College of Engineering, Guntur, India
}

\begin{abstract}
This paper presents a novel control strategy based on variable structure theory (VST) for the generator side converter to regulate the dc link voltage of a direct driven PMSG wind energy conversion system (WECS). The validity of the technique is theoretically analyzed, and the design procedure is presented. The primary merit of the proposed technique is that it does not require an anemometer or prior knowledge of a system, but has an accurate and fast dynamic response to wind speed fluctuations. Modeling of Wind turbine, PMSG, controlling of generator side switch mode converter and Simulation results are presented. Simulation is done in MATLAB/POWERSYSTEM environment.
\end{abstract}

\section{Index terms}

Variable-speed wind turbine, PMSG, VSCS, SMC and switch-mode rectifier (SMR).

\section{INTRODUCTION}

In recent years, the renewable energy sources have promising solution for power paucity problems and for a cleaner and economical energy society. Among all available wind energy conversion systems (WECS), the direct driven Permanent magnet synchronous generator variable speed WECS systems integrated with power electronic interfaces are becoming popular due to their capability of extracting optimal energy capture, reduced mechanical stresses and aerodynamic noise [1]. The amount of energy capture from a WECS depends not only on the wind at the site, but depends on the control strategy used for the WECS and also depends on the conversion efficiency. PMSG has received much attention in wind-energy application because of their property of selfexcitation, which allows an operation at a high power factor and high efficiency [2]. The use of permanent magnet in the rotor of the PMSG makes it unnecessary to supply magnetizing current through the stator for constant air-gap flux; the stator current need only to be torque producing. Hence, for the same output, the PMSG will operate at a higher power factor because of the absence of the magnetizing current and will be more efficient than other machines.

Direct driven PMSG WECS is needs a full scale power conversion to interface the generator with the Grid. The most popular grid connected topology of a direct driven PMSG variable speed WECS is the back-to-back converter. The characteristics of the back-to-back converter are that the converter utilizes active devices at both the generator side for the rectifier and the grid side for the inverter [3]. The major disadvantage of back-to-back topology is, the controller is complex and expensive because it requires 12-channel Pulse

Width Modulation (PWM) signals for the rectifier and the inverter. For this reason, in a practical application, the control system requires at least two or more Micro-Controller Units (MCU), Digital Signal Processor (DSP), Field Programmable Gate Array (FPGA), etc. to control the chips on the board. A simple topology for wind turbine generation was introduced in [4] which consist of a diode bridge rectifier, with a DC link to an active IGBT inverter. Although this type of converter is simple and reliable, but the power factor of the generator is low. The other problem is that when the output voltage of the rectifier is lower than the grid, power cannot be injected to the grid. By summarizing the topology of back-to-back and diode rectifier, it is possible to insert a boost circuit between the diode rectifier and the Grid side inverter, in order to solve the issue of generator power factor [5]. For this topology of converter, operation at relatively low wind speeds is possible due to the inclusion of the boost circuit. The boost circuit maintains the DC bus link voltage at a constant value. This topology is utilized in this work.

However, the dc link voltage fluctuates due to wind speed variations, which will increase the dc link capacitor. Therefore, several literatures regarding the stabilization of dc link voltage have been published, such as of intermediate chopper. In [6], constant dc link voltage is maintained by using intermediate dc-dc converter. In [7], constant dc link voltage is obtained by controlling the generator side converter. But this technique involves measuring the power generated by PMSG.

A novel control strategy for the generator side SMR to regulate the dc link voltage is developed, which is derived from the variable structure systems (VSS) theory [8]-[9]. The generatorside switch-mode rectifier is controlled to regulate the dc link voltage and to maintain the sinusoidal stator currents. The method requires only one active switching device [insulated gate bipolar transistor (IGBT)], which is used to control the generator torque and to regulate the dc link voltage. It is simple and a low-cost solution for a small-scale wind turbine and it doesn't require measuring the power generated by PMSG. There are a number of papers which discussed the control strategy of grid side converter for direct driven PMSG WECS. Effectiveness of the proposed method is verified by the numerical simulations using MATLAB/POWERSYSTEM.

\section{SYSTEM OVERVIEW}

Fig. 1 shows the control structure of a generator side converter of PMSG-based variable-speed wind turbine which include a wind turbine, PMSG, single-switch three-phase switch mode rectifier, and a vector-controlled PWM voltage source inverter.The output of a variable-speed PMSG is not suitable for use as it varies in amplitude and frequency due to fluctuating wind. A constant DC voltage is required for direct use, storage, or conversion to $\mathrm{AC}$ via an inverter. In this paper, a single switch three-phase switch-mode rectifier is used to convert the ac output voltage of the generator to a 
constant DC voltage before conversion to AC voltage via an inverter. The single-switch three-phase switch-mode rectifier consists of a three-phase diode bridge rectifier and a dc to dc converter. The output of the switch-mode rectifier can be controlled by controlling the duty cycle of an active switch (such as IGBT) at any wind speed to control the DC link voltage.

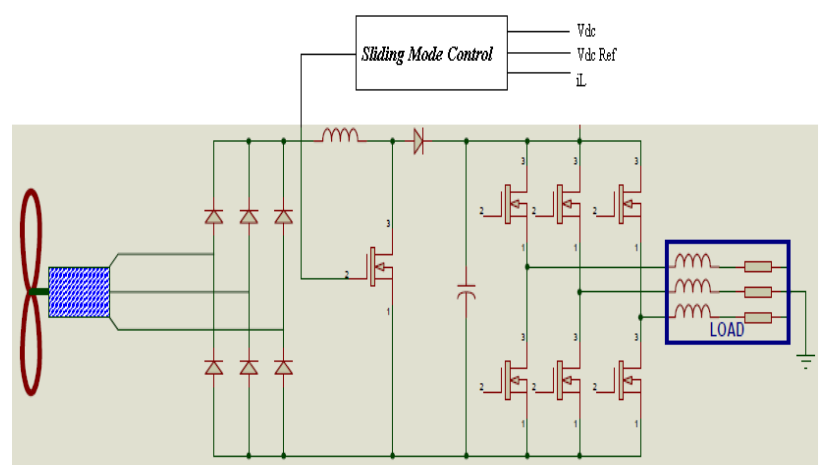

Fig 1. Wind turbine with diode rectifier and boost circuit

\subsection{Wind Turbine Characteristics}

The amount of power captured by the wind turbine (power delivered by the rotor) is given by

$$
p_{t}=0.5 \rho A C_{p}(\lambda, \beta) \times\left(v_{w}\right)^{3}=0.5 \rho A C_{p} \times\left(\frac{w_{m} R}{\lambda}\right)^{3}
$$

where $\rho$ is the air density (kilograms per cubic meter), $v_{\omega}$ is the wind speed in meters per second, $A$ is the blades' swept area, and $C_{p}$ is the turbine-rotor-power coefficient, which is a function of the tip-speed ratio $(\lambda)$ and pitch angle $(\beta) . \omega_{m}=$ rotational speed of turbine rotor in mechanical radians per second, and $R=$ radius of the turbine. The coefficient of performance of a wind turbine is influenced by the tip-speed to wind-speed ratio, which is given by

$\mathrm{TSR}=\lambda=\left(\omega_{\mathrm{m}} \mathrm{R} / \mathrm{v}_{\mathrm{w}}\right)$

The wind turbine can produce maximum power when the turbine operates at maximum $\mathrm{C}_{\mathrm{p}}$ (i.e., at $\mathrm{C}_{\mathrm{p}_{-} \text {opt }}$ ). Therefore, it is necessary to keep the rotor speed at an optimum value of the tip-speed ratio $\lambda_{\text {opt }}$. If the wind speed varies, the rotor speed should be adjusted to follow the change. The target optimum power from a wind turbine can be written as

$\mathrm{P}_{\mathrm{m}_{\text {_opt }}}=0.5 \rho \mathrm{AC} \mathrm{C}_{\mathrm{p} \_ \text {opt }} \times\left(\frac{\mathrm{w}_{\mathrm{m} \_ \text {opt }} \mathrm{R}}{\lambda_{\text {opt }}}\right)^{3}=\mathrm{K}_{\mathrm{opt}}\left(\mathrm{w}_{\mathrm{m}_{\text {_opt }}}\right)^{3}$

Where

$\mathrm{K}_{\mathrm{opt}}=0.5 \rho \mathrm{AC}_{\mathrm{p}_{\mathrm{oppt}}} \times\left(\frac{\mathrm{R}}{\lambda_{\mathrm{opt}}}\right)^{3}$

$\mathrm{w}_{\mathrm{m} \_ \text {opt }}=\frac{\lambda_{\text {opt }}}{\mathrm{R}} \mathrm{v}_{\mathrm{w}}=\mathrm{K}_{\mathrm{w}} \mathrm{v}_{\mathrm{w}}$

Therefore, the target optimum torque can be given by

$\mathrm{T}_{\mathrm{m} \_ \text {opt }}=\mathrm{K}_{\text {opt }}\left(\mathrm{w}_{\mathrm{m} \_ \text {opt }}\right)^{2}$

The mechanical rotor power generated by the turbine as a function of the rotor speed for different wind speed is shown in Fig.2. The optimum power is also shown in this figure. The optimum power curve $\left(P_{\text {opt }}\right)$ shows how maximum energy can be captured from the fluctuating wind. The function of the controller is to keep the turbine operating on this curve, as the wind velocity varies. It is observed from this figure that there is always a matching rotor speed which produces optimum power for any wind speed. If the controller can properly follow the optimum curve, the wind turbine will produce maximum power at any speed within the allowable range. The optimum torque can be calculated from the optimum power given by (6). For the generator speed below the rated maximum speed, the generator follows (6).

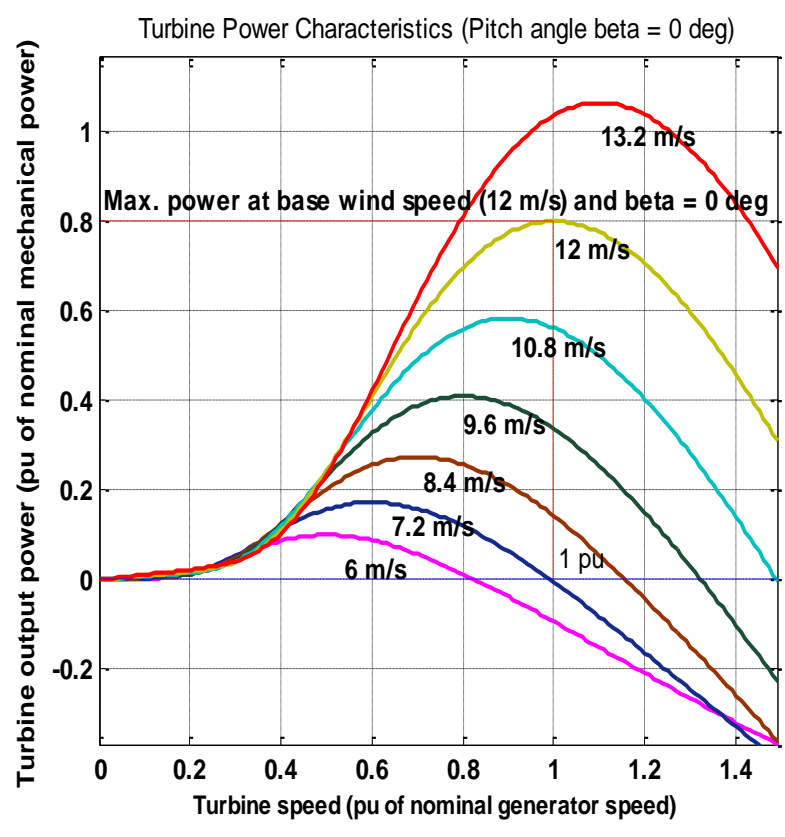

Fig.2. Mechanical power generated by the turbine as a function of the rotor speed for different wind speeds.

\subsection{PMSG Model}

Basically, the mass model of a PMSG is the same as that of a permanent magnet synchronous motor (PMSM). The voltage and torque equations of the PMSM in the $d-q$ reference frames are given by the following equations [1013]:

$v_{d}=R_{a} i_{d}+L_{d} \frac{d i_{d}}{d t}-\omega_{c} L_{q} i_{q}$

$\mathrm{v}_{\mathrm{q}}=\mathrm{R}_{\mathrm{a}} \mathrm{i}_{\mathrm{q}}+\mathrm{L}_{\mathrm{q}} \frac{\mathrm{di}_{\mathrm{q}}}{\mathrm{dt}}+\omega_{\mathrm{c}} \mathrm{L}_{\mathrm{d}} \mathrm{i}_{\mathrm{d}}+\omega_{\mathrm{c}} \mathrm{K}$

$\mathrm{T}_{\mathrm{e}}=\mathrm{p}\left\{\mathrm{Ki}_{\mathrm{q}}+\left(\mathrm{L}_{\mathrm{d}}-\mathrm{L}_{\mathrm{q}}\right) \mathrm{i}_{\mathrm{d}} \mathrm{i}_{\mathrm{q}}\right\}$

where $v_{d}$ and $v_{q}$ are the $d q$-axis voltages, $i_{d}$ and $i_{q}$ are the $d q$ axis currents, $R_{a}$ is the stator resistance, $L_{d}$ and $L_{q}$ are the $d q$ axis inductances, $\omega_{e}$ is the generator rotational speed, $K$ is the permanent magnetic flux, and $p$ is the number of pole pairs. Generating operation starts when the electromagnetic torque $T e$ is negative. The motion equation of the PMSG is given as follows:

$\mathrm{T}_{\mathrm{e}}=\mathrm{T}_{\omega}+\mathrm{J}_{\mathrm{eq}} \frac{\mathrm{d} \omega_{\mathrm{m}}}{\mathrm{dt}}+\omega_{\mathrm{m}} \mathrm{D}$

\section{CONTROL OF SMR FOR CONSTATNT DC-LINK VOLTAGE}

The control objective is to control the duty cycle of the switch in Fig. 2 to regulate the DC link voltage. Control of switch-mode power supplies can be difficult, due to their intrinsic non-linearity. In fact, control should ensure system stability in any operating conditions and good transient and steady state performances in terms of rejection of wind velocity disturbances and decrease the effect of parameter variations (robustness). A different approach, which complies with the non-linear nature of switch-mode power rectifier, is represented by the sliding mode control, which is derived from the variable structure systems (VSS) theory.

\subsection{Control of Variable Structure Systems}

VSS are systems whose physical structure is changed intentionally during the time in accordance with a preset structure control law. The instants at which the changing of the structure occur are determined by the current state of the system. From this point of view, switch-mode power supplies represent a particular class of VSS, since their structure is 
periodically changed by the action of controlled switches and diodes. During the control process, the structure of the control system varies from one structure to another thus earning the name variable structure control (VSC).

VSC is a high-speed switching feedback control resulting in a sliding mode. For example, the gains in each feedback path switch between two values according to a rule that depends on the value of the state at each instant. The purpose of the switching control law is to drive the nonlinear plant's states trajectory on this surface for all subsequent time. This surface is called Switching Surface. When the plants state trajectory is "above" the surface, feedback path has one gain and a different gain if the trajectory drops "below" the surface. This surface defines the proper rule for switching. The surface is also called Sliding Surface because, ideally speaking, once intercepted, the switching control maintains the plant's state trajectory on the surface for all subsequent time and the plant's state trajectory along this surface. The plant dynamics restricted to this surface represent the controlled system behavior.

A VSC control design breaks into two phases.

- The first phase is to design or choose a switching surface so that the plant state trajectory restricted to the surface has desired dynamics.

- The second phase is to design a switched control that will drive the plant state to the switching surface and maintain into on the surface upon interception.

A lyapunov approach is used to characterize this second design phase. Here a generalized lyapunov function, that characterizes the motion of the state trajectory to the surface, is defined in terms of the surface. For each chosen switched control structure, one chooses the "gains" so that the derivative of this lyapunov function is negative definite, thus guaranteeing motion of the state trajectory to the surface. To emphasize the important role of the Sliding mode, the control is also called Sliding mode control. It should be noted that a variable structure control system can be devised without a sliding mode, but such system does not possess the associated merits.

\subsection{System Model, and Control Structure}

Let us consider now a class of systems with a state model nonlinear in the state vector $\mathrm{x}($.$) and linear in the control vector$ $\mathrm{u}($.$) in the form$

$\mathrm{x}(\mathrm{t}) \in \mathrm{R}^{\mathrm{m}}$

Where $x(t) \in R^{m}$, and $B(x, t) \in R^{n \times m}$ further, each entry in $f(x, t)$ and $B(x, t)$ is assumed continuous with a bounded continuous derivative with respect to $\mathrm{x}$.

The first phase is to designed or chooses a switch surface so that the plant state trajectory restricted to the surface has desired dynamics. According to the Sliding mode control theory [8], all state variables area sensed, and the states are multiplied by proper gains $K_{i}$ and added together to form the sliding function $\sigma(\mathrm{x}, \mathrm{t})$ hysteretic block maintains this function to zero, so that we can define sliding surface as:

$\sigma(\mathrm{x}, \mathrm{t})=\sum_{1}^{\mathrm{N}} \mathrm{K}_{\mathrm{i}} \mathrm{x}_{\mathrm{i}}=0$

Where $\mathrm{N}$ is the system order (number of state variables)

For second order systems

$\sigma=\mathrm{x}_{1}+\tau \mathrm{x}_{2}$

This is a linear combination of the two state variables. In the phase plane, equation $\sigma=0$ represents a line, called sliding line, passing through the origin (Which is the final equilibrium point for the system).

We now define the following control strategy

If $\sigma>+\beta \Rightarrow \mathrm{u}=0$

If $\sigma>-\beta \Rightarrow u=1$
Where $\beta$ define a suitable hysteresis band. In this way, the phase plane is divided in two regions separated by the sliding line, each associated to one of the two sub topologies defined by switch status $u$. When the system status is in P, Since we are in the region $\sigma<-\beta$, the switch is closed and the motion occurs along a phase trajectory corresponding to $u=1$. When the system status crosses the line $\sigma=+\beta$, according to (14), $u=0$ and the system status follows a phase trajectory corresponding to $u=1$. observing that the phase trajectories, in proximity of the sliding line, are directed toward the line itself, the resulting motion is made by continuous commutations around the sliding line, so that the system status is driven to the final equilibrium point.

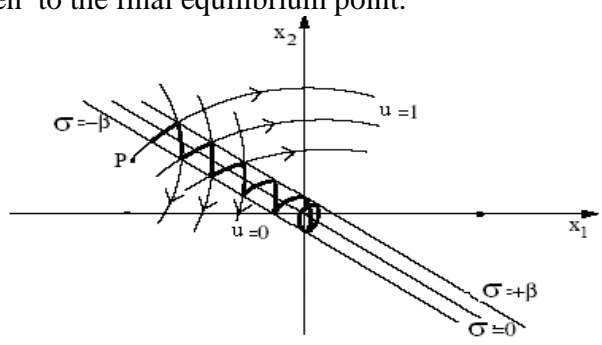

Fig.3. Sliding surface

From this example, in the hypothesis of a suitable small value of $\beta$, two important conclusions arise

- When the system is in the sliding mode, its evolution is independent of the system parameters. It depends only on the sliding line chosen. In the example shown in Fig.3 the dynamic is of the first order with a time constant equal to $\tau$.

- If $\mathrm{N}$ is the order of the original system, the dynamic of the controlled system in sliding mode has order $\mathrm{N}-1$, since the state variables are constrained by the equation $\sigma=0$.

Note that the switching frequency is determined by the amplitude of the hysteresis band $\beta$. The potentialities of this control technique in the application to switch to switch-mode power supplies are now evident: it exploits the intrinsic nonlinear nature of these converters and it is able to provide dynamic behaviors that are different from that of the substructures composing the system, and correspond to that of a reduced system.

\section{Switching surface design}

In the simple case of the second-order systems considered in the previous section, sliding mode control design requires only selection of parameter $\tau$. Selection, must be done in order to ensure the following three constraints The hitting condition, which requires that the system trajectories cross the sliding line irrespective of their starting point in the phase plane; The existence condition, which requires that the system trajectories near the sliding line (in both regions) are directed toward the line itself; The stability condition of the system motion on the sliding line (i.e. the motion must be toward the equilibrium point).

\section{Existence Condition:}

The existence condition requires that the phase trajectories are directed toward the sliding surface in a small volume around the surface itself. It is achieved by defining the appropriate Lyapunov function $V(x, t, \sigma)$. For signal input systems it is ordinarily convenient to choose a Lyapunov function of the form $V(x, t, \sigma)=0.5 \sigma^{2}(\mathrm{x})$. To determine the gains necessary to drive the system state to the surface $\sigma(\mathrm{t})=0$, they may be choose so that

$\dot{V}(x, t, \sigma)=0.5 \frac{\mathrm{d} \sigma^{2}}{\mathrm{dt}}=\sigma(\mathrm{x}) \frac{\mathrm{d} \sigma(\mathrm{x})}{\mathrm{dt}}=\sigma . \dot{\sigma}<0$ 
Thus sliding mode does exist on a discontinuity surface whenever the distances to this surface and the velocity of its change $\dot{\sigma}$ are of opposite signs, i.e. when

$\lim _{x \rightarrow+0} \dot{\sigma}>0$ and $\lim _{x \rightarrow-0} \dot{\sigma}<0$

\section{Stability Condition}

Switching surface design is predicted upon knowledge of the system behavior in a sliding mode. This behavior depends on the parameters of the switching surface. In any case, achieving a switching-surface design requires analytically specifying the motion of the state trajectory in a sliding mode. The so called method of equivalent control is essential to this specification.

\section{Equivalent Control:}

Equivalent control constitute an equivalent input which, when exciting the system, produces the motion of the system on the sliding surface whenever the initial state is on the surface. Suppose at $t_{1}$ the plant's state trajectory intercepts the switching surface, and a sliding mode exists. The existence of a sliding mode implies that, for all $t \geq t_{1}, \sigma(x(t), t)=0$ and hence $\dot{\sigma}(x(t), t)=0$. Using the chain rule, we define the equivalent control $u_{e q}$ for system as the input satisfying

$\dot{\sigma}=\frac{\partial \sigma}{\partial \mathrm{t}}+\frac{\partial \sigma}{\partial \mathrm{x}} \dot{\mathrm{x}}=\frac{\partial \sigma}{\partial \mathrm{t}}+\frac{\partial \sigma}{\partial \mathrm{x}} \mathrm{f}(\mathrm{x}, \mathrm{t})+\frac{\partial \sigma}{\partial \mathrm{x}} \mathrm{B}(\mathrm{x}, \mathrm{t}) \mathrm{u}_{\mathrm{eq}}=0$

Assume that the matrix product $\frac{\partial \sigma}{\partial x} \mathrm{~B}(\mathrm{x}, \mathrm{t})$ is nonsingular for all $t$ and $x$, and one can compute $u_{e q}$ as

$\mathrm{u}_{\mathrm{eq}}=-\left[\frac{\partial \sigma}{\partial \mathrm{t}} \mathrm{B}(\mathrm{x}, \mathrm{t})\right]^{-1}\left(\frac{\partial \sigma}{\partial \mathrm{t}}+\frac{\partial \sigma}{\partial \mathrm{x}} \mathrm{f}(\mathrm{x}, \mathrm{t})\right)$

Therefore, given that $\sigma\left(x\left(\mathrm{t}_{1}, \mathrm{t}_{1}\right)\right)=0$, then for all $t \geq t_{1}$, the dynamics of the system on the switching surface will satisfy $\dot{\mathrm{x}}(\mathrm{t})=$

$\left[1-B(x, t)\left[\frac{\partial \sigma}{\partial \mathrm{x}} \mathrm{B}(\mathrm{x}, \mathrm{t})\right]^{-1} \frac{\partial \sigma}{\partial \mathrm{x}}\right] f(x, t)-B(x, t)\left[\frac{\partial \sigma}{\partial \mathrm{x}} \mathrm{B}(\mathrm{x}, \mathrm{t})\right]^{-1} \frac{\partial \sigma}{\partial \mathrm{t}}$

This equation represents the equivalent system dynamics on the sliding surface. The driving term is present when some form of tracking or regulation is required of the controlled system, e.g. when

$\sigma(\mathrm{x}, \mathrm{t})=\sum_{1}^{\mathrm{N}} \mathrm{K}_{\mathrm{i}} \mathrm{x}_{\mathrm{i}}+\mathrm{r}(\mathrm{t})=0$

With $r(t)$ serving as a "reference" signal.

\subsection{Physical Meaning of the Equivalent Control}

A real control always includes a slow component to which a high rate component maybe added. So decompose the control structure as

$\mathrm{u}(\mathrm{x}, \mathrm{t})=\mathrm{u}_{\mathrm{eq}}(\mathrm{x}, \mathrm{t})=\mathrm{u}_{\mathrm{N}}(\mathrm{x}, \mathrm{t})$

Where $u_{e q}$ is only valid on the sliding surface and $u_{N}$ assures the existence of a sliding mode. And $u_{N}$ is defined as $\mathrm{u}_{\mathrm{N}}(\mathrm{x}, \mathrm{t})=\operatorname{sgn}(\sigma)$

$$
\text { Where } \operatorname{sgn}(\sigma)=\frac{\sigma}{|\sigma|}
$$

Since a control plant is a dynamic object, its behavior is largely determined by the slow component while its response to the high rate component is negligible. On the other hand, the equivalent control method demands a substitution of the real control in the motion Eq (20) with a continuous function $u_{e q}$ $(x, t)$, which does not contain any high rate component. The equivalent control equals the slow component of the real control i.e. average control value and may be measured by a first order linear filter provided its time constant is small enough as compared with the slow component, yet large enough to filter out the high rate component and approximately matched with the boundary layer width.

\subsection{Link Voltage Regulation using Sliding Mode Control}

The control objective of the regulation problem is to drive the states to zero. When matched uncertainty alone is present, the nominal linear system representation is considered when designing the switching function. In this work a new variation of Sliding mode control of SMR based on Quasi-Steady-State is proposed.

\section{System Model}

Taking into account that the cut-off frequency of the filter is much higher the line frequency, the resulting close loop dynamic behavior of the boost Power Factor Correction rectifier can be approximated by the following relations:

$\mathrm{i}_{\mathrm{s}}=\mathrm{i}_{\mathrm{L}} \operatorname{sgn}\left(\mathrm{V}_{\mathrm{s}}\right)$

$\mathrm{L} \frac{\mathrm{di}_{\mathrm{L}}}{\mathrm{dt}}=\left|\mathrm{V}_{\mathrm{s}}\right|-\mathrm{V}_{\mathrm{o}} \cdot \mathrm{u}_{\mathrm{eq}}$

$C \frac{d V_{o}}{d t}=i_{L} u_{e q}-\frac{v_{o}}{R}$ Where $u_{\mathrm{eq}}$ is the average values of the control variable $u(u=0$ when switch is on and $u=1$ when switch is off), $\mathrm{i}_{\mathrm{L}}$ is the boost inductor current, $i_{\mathrm{s}}$ is the $\mathrm{AC}$ source current, $\mathrm{V}_{\mathrm{o}}$ is the boost converter output voltage $\mathrm{V}_{\mathrm{s}}$ is the $\mathrm{AC}$ rms voltage.

\section{Controller Design}

The input current of a Active Power Factor Correction must fallow the shape the line voltage as a resistor, and simultaneously, the average value of the output voltage $\left(\left\langle V_{o}\right\rangle\right)$ must be regulated to a reference value $\left(V_{o}\right.$ ref $)$. both control goals be achieved if the input current satisfies the following relation.

$\mathrm{i}_{\mathrm{L}}=\frac{\left|\mathrm{V}_{\mathrm{s}}\right|}{\mathrm{R}_{\mathrm{eq}}}$

Where $i_{L}$ is the inductor current of the converter and $R_{e q}$ is the emulated resistor the values of which are related to the input power and the output voltage. The value of $R_{e q}$ must be controlled to make the average value $\left\langle V_{o}\right\rangle$ follow a reference value $V_{o}$ ref. The control scheme consists of both an outer control loop, which regulates the value of the emulated resistor, and an inner control loop, which is used to make the input current follow a reference value $\frac{\left|V_{s}\right|}{R_{e q}}$.

To implement the relation of Eq. (25), avoiding the sensing of the line voltage and the use of an analogue multiplier, the quasi-steady-state approach is considered. According to the approach, the ratio between the line and the output voltage can be approximated by the voltage conversion ratio of a DC/DC boost converter. Therefore, the following relationship can be used in the control design

$\frac{\left|\mathrm{V}_{\mathrm{o}}\right|}{\left|\mathrm{v}_{\mathrm{s}}\right|} \approx \frac{1}{\langle u\rangle}$

Where $\langle\mathrm{u}\rangle$ is the average value of the control variable $\mathrm{u}$ during a switching period ( $u=0$ when switch is on and $u=1$ when switch is off).

Substituting Eq.(26) for Eq.(27) yields a new expression of the control goal is

$\mathrm{i}_{\mathrm{L}}=\frac{\mathrm{v}_{\mathrm{o}}<u>}{\mathrm{R}_{\mathrm{eq}}}$

Taking into the account that $\mathrm{i}_{\mathrm{L}}$ and $\mathrm{V}_{\mathrm{o}} / \mathrm{R}_{\mathrm{eq}}$ are nearly constant during a switching period, the relation eq. can be approximated by

$\left\langle\mathrm{i}_{\mathrm{L}}-\mathrm{K} . \mathrm{u}\right\rangle \approx 0$

$H_{L P}(s)\left(\mathrm{i}_{\mathrm{L}}-\mathrm{K} . \mathrm{u}\right) \approx 0$

Where $\mathrm{K}$ is defined as $\mathrm{V}_{\mathrm{o}} / \mathrm{R}_{\mathrm{eq}}$, and it is the new control variable which is used to regulate the output voltage. In order to achieve the unity-power-factor, the expression (28) must be satisfied when the sliding regime is reached. The expression of this required sliding surface can be deduced by identifying the invariance condition $\sigma=0$ with Eq.(28).

$\sigma=H_{L P}(s)\left(\mathrm{i}_{\mathrm{L}}-\mathrm{K} . \mathrm{u}\right)$

Note that this sliding surface will satisfy the transversal condition if $H_{L P}(s)$ is the first order low pass filter $\left(H_{L P}(s)=s_{d} s+s_{o}\right)$, it can be used to calculating the average value of $i_{L}-K$. $u$ during a switching period. The control law 
associated with this surface is deduced by using the reaching condition, $\sigma . \dot{\sigma}<0[8]$, which yields

$$
u=\left\{\begin{array}{l}
1 \ldots \ldots \ldots . \text { when } \sigma>0 \\
0 \ldots \ldots \ldots \text { when } \sigma<0
\end{array}\right.
$$

Moreover, a proportional-integral control of $\mathrm{K}$ has been used to make the output voltage be regulated to a reference value $V_{\text {o ref. }}$

$$
\mathrm{K}=\mathrm{K}_{\mathrm{p}}\left(\mathrm{V}_{\text {oref }}-\mathrm{V}_{\mathrm{o}}\right)+\mathrm{K}_{\mathrm{I}} \int_{0}^{\mathrm{t}}\left(\mathrm{V}_{\text {oref }}-\mathrm{V}_{\mathrm{o}}\right) \mathrm{d} \tau
$$

Fig. 1 shows the block diagram of proposed controller. In order to implement the proposed sliding surface, a first order low-pas filter, an analog multiplexer, and a proportional integral controller are required. Finally, the state of the switch is determined by a hysteresis comparator, according to the control law deduced above.

\section{RESULTS AND DISCUSSION}

The model of the PMSG-based variable-speed windturbine system of Fig. 1 is built using Matlab/Simpowersystem simulation software. The simulation model is developed based on a 6-kW permanent-magnet synchronous machine. The power converter and the control algorithm are also implemented and included in the model. Fig. 4 shows the response of the system for a step change of wind speed from $10(0.2 \mathrm{Sec})$ to $12(0.4 \mathrm{Sec})$ to $9 \mathrm{~m} / \mathrm{s}(0.6 \mathrm{Sec})$, and then back to 10 $\mathrm{m} / \mathrm{s}$. Fig. 4 shows the dc-link voltage, PMSG stator voltage, PMSG stator current. It is seen from Fig. 4(a) dc link voltage is well maintained at a constant-load condition.

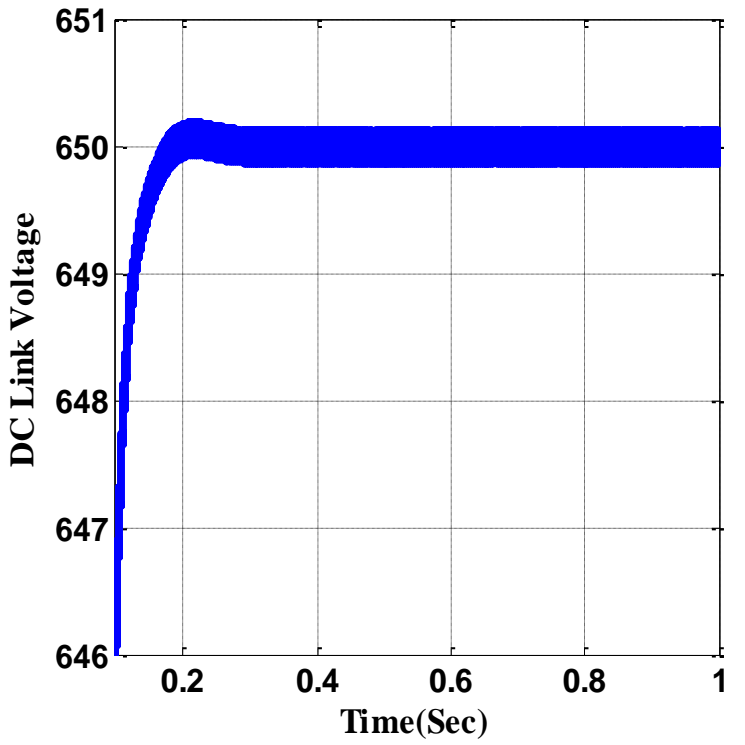

Fig.4 (a) DC Link Voltage

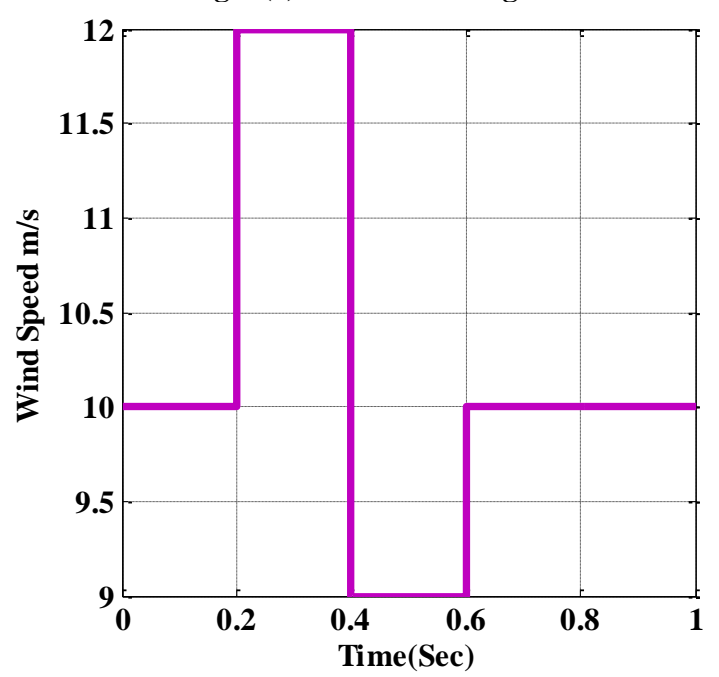

Fig.4 (b) Wind Profile

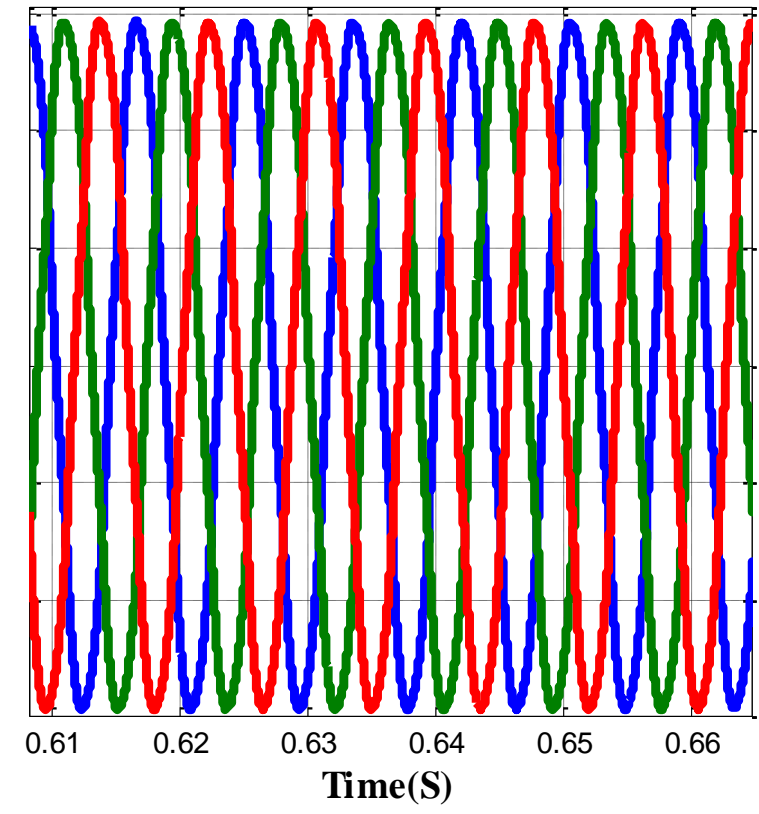

Fig.4 (c) PMSG Stator Currents

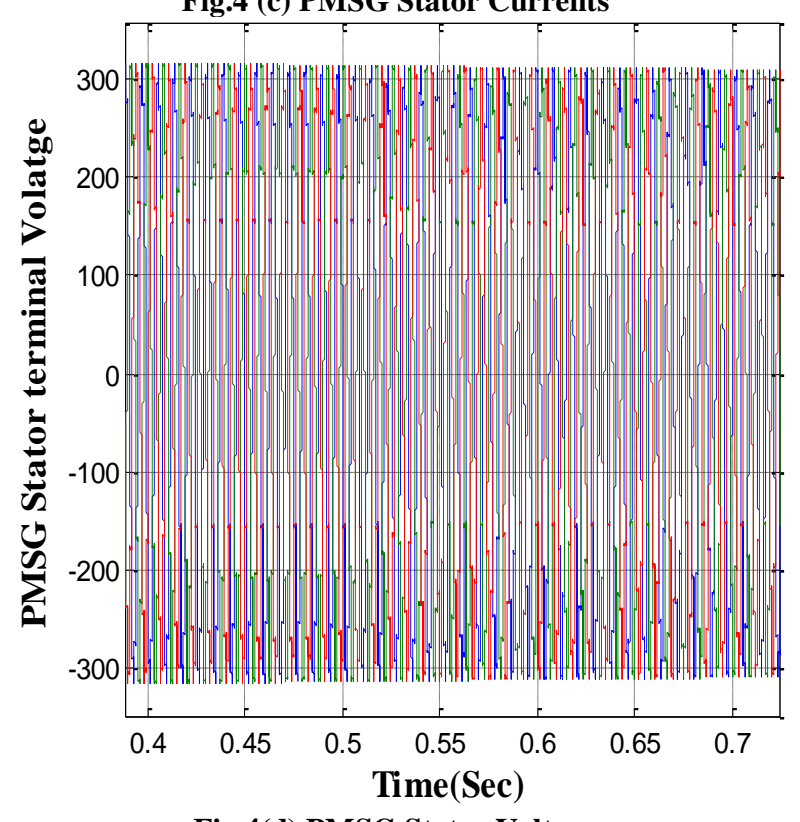

Fig 4(d) PMSG Stator Voltage

\section{CONCLUSION}

A novel control strategy for a direct-drive PMSG variable speed wind turbine has been presented in this paper. A simple control strategy for the generator-side converter to regulate the dc link voltage is discussed and implemented using MATLAB/Simpowersystem simulation software. The proposed controller is capable of maintaining the constant $\mathrm{dc}$ link voltage of the variable-speed wind turbine under fluctuating wind. The simulation results demonstrate that the controller works very well and shows very good dynamic and steady-state performance.

\section{REFERENCES}

[1]. H. Polinder, F. F. A. Van der Pijl, G. J. de Vilder, and P. J. Tavner, "Comparison of direct-drive and geared generator concepts for wind turbines,"IEEE Trans. Energy Convers., vol. 3, no. 21, pp. 725-733, Sep. 2006 
[2]. T. F. Chan and L. L. Lai, "Permanent-magnet machines for distributed generation: A review," in Proc. IEEE Power Eng. Annu. Meeting, 2007,pp. 1-6.

[3]. Bharanikumar R., Yazhini A.C., \& Kumar "Modeling and Simulation of Wind Turbine Driven Permanent Magnet Generator with New MPPT". Asian Power Elevtronics Journal, Vol. 4, (2) 52-58, 2010.

[4]. Ahmed T., Nishida K., \& Nakaoka M. 2004, "Wind Energy DC Supply-Based Induction Generator with Static VAR Compensator and AC Voltage Regulator", In INTELEC 2004, 26th Annual International, IEEE, pp. 689-696.

[5]. Belakehal S., Benalla H., \& Bentounsi. "Power Maximumization Control of Small Wind System Using Permanent Magnet Synchronous Generator". Revuedes Energies Renouvelables, 12, (2) ,2009,307-319.

[6]. Ki-Hong Kim, Yoon-Cheul Jeung, Dong-Choon Lee, Heung-Geun Kim, "LVRT Scheme of PMSG Wind Power Systems Basedon Feedback Linearization” IEEE transactions on power electronics, vol. 27, no. 5, pp.2376-2384, May 2012.

[7]. Akie Uehara,Alok Pratap,Tomonori Goya, Tomonobu Senjyu, Atsushi Yona, Naomitsu Urasaki, and Toshihisa Funabashi, "A Coordinated Control Method to Smooth Wind Power Fluctuations of a PMSG-Based WECS" IEEE Transactions On Energy Conversion, Vol. 26, No. 2, pp.550-558,June 2011.

[8]. J.Y.Yung, W. Gao and J.C.Hung, "Variable Structure Control: A Survey", IEEE Trans. Ind. Electronics, vol 40, pp.2-22.Feb.1993.

[9]. R.A. Decarlo, S.H. Zak, S.V.Drakunov, "Varaible Structure, Sliding Mode Control Design", Control System Hand Book, pp:941-951

[10] M. Singh and A. Chandra, "Application of adaptive network-based fuzzy inference system for sensorless control of PMSG-based wind turbine with nonlinearload-compensation capabilities," IEEE Trans. Power Electron., vol. 26, no. 1, pp. 165-175, Jan. 2011.
[11] T. H. Nguyen, S.-H. Jang, H.-G. Park, and D.-C. Lee, "Sensorless control of PM synchronous generators for micro wind turbines," in Proc. IEEE 2nd Int. Power Energy Conf., Dec. 2008, pp. 936-941.

[12] J. Dai, D. Xu, B.Wu, and N. R. Zargari, "Unified DClink current control for low-voltage ride-through in current-source-converter-based wind energy conversion systems," IEEE Trans. Power Electron., vol. 26, no. 1 , pp. 288-297, Jan. 2011.

[13] G. Foo and M. F. Rahman, "Sensorless direct torque and flux-controlled IPM synchronous motor drive at very low speed without signal injection," IEEE Trans. Power Electron., vol. 57, no. 1, pp. 395-403, Jan. 2010.

\section{AUTHOR'S PROFILE}

K.Rama Lingeswara Prasad received the B. Tech from the Department of EE engineering Nagarjuna University, India in 2002 and M.Tech from the Department of Electrical Engineering, Govt.College of Engineering, Pune, India in 2005. He worked as R\&D Engineer in Amararaja Power systems, Karakambadi, Tirupathi form Aug 2005 to July 2006 . Presently working for Lakireddy Bali Reddy College of Engineering as Assoc. Professor in the Department of Electrical Electronics Engineering, Mylavaram, India and currently pursuing the Ph.D. degree at Acharya Nagarjuna University,Guntur,India. His research interests include ac-dc converter with power factor correction,WECS,SMPS and Active power filters for Harmonic compensation.

Dr.K.ChandraSekhar received his B.Tech degree in Electrical \& Electronics Engineering from V.R.Siddartha Engineering College, Vijayawada, India in 1991 and M.Tech with Electrical Machines \& Industrial Drives from Regional Engineering College, Warangal, India in 1994. He Received the $\mathrm{PhD}$ degree from the J.N.T.U College of Engineering, Hyderabad, India in 2008. He is having 17 years of teaching experience. $\mathrm{He}$ is currently Professor and Head of Department, EEE, R.V.R \& J.C.College of engineering, Guntur, India. His Research interests are Power Electronics, Industrial Drives \& FACTS Devices. 